\title{
SOSTENIBILIDAD Y GOBERNANZA
}

\author{
Armando Menéndez Viso \\ Department of Sociology and Philosophy University of Exeter
}

\begin{abstract}
The word "sustainability" is nowadays commonly related to a fuzzy array of concepts, like nature, environment, ecology, preservation or development. The first task of this chapter will be to establish some clear limits to that fuzzy set of ideas, correcting its environmental bias and stressing its moral elements. Once defined, it will be possible to check whether the notion of sustainability could help in achieving good governance, and how. It will be shown that, although sustainability works well as a filter -especially to discard damaging policies-, it has no political content at all. Sustainability could constitute a useful rhetorical resource, but it is absolutely meaningless without being associated to a concrete discourse or proposal.
\end{abstract}

KEY WORDS Sustainability, sustainable development, governance, environment.

"Sólo hay una alternativa a la sostenibilidad: la insostenibilidad"

(Bossel, 1999)

\section{Introducción}

La sostenibilidad -palabra que, de momento ${ }^{1}$, no recoge el diccionario de la R.A.E.- no se deja definir más que como la cualidad de sostenible. $Y$ sostenible es todo lo que puede sostenerse. No debe pasarse por alto que este "puede" es susceptible de recibir dos interpretaciones igualmente pertinentes para la tarea que estamos emprendiendo: poder como capacidad ("lo que no se puede no se puede y además es imposiblen) y poder como deber (como cuando se dice que no se pueden bajar animales a la playa o que la corrupción política no puede consentirse).
RESUMEN Si a una persona no especialmente informada se le habla hoy de sostenibilidad, lo más probable es que acuda a su cabeza una serie de ideas comúnmente asociadas al término: naturaleza, medio ambiente, ecología, conservación, desarrollo, etc. La primera tarea de estas páginas consistirá, precisamente, en especificar, filtrar y acaso extender esta serie de ideas. Después se intentará averiguar si puede ayudar a emprender una buena acción de gobierno, y cómo. La conclusión a la que se llegará es que la sostenibilidad resulta eficaz como criterio de selección -especialmente para descartar acciones de gobierno perniciosas- y debe desempeñar el papel de un ideal regulativo, pero no ofrece programas concretos de buen gobierno. La retórica de la sostenibilidad da juego (permite al menos cuatro figuras recurrentes, como se verá), pero no proporcionará resultado alguno si el discurso que recurre a ella no posee su propio contenido.

PALABRAS CLAVE Sostenibilidad, desarrollo sostenible, gobernanza, medio ambiente.
A menudo se habla también de sustentabilidad, mas el empleo de este término deja escapar un campo semántico que en castellano sí recoge la sostenibilidad: el de lo moralmente soportable. Es verdad que, en uso directo, los verbos sostener y sustentar son prácticamente sinónimos, pero el primero ha alcanzado también un uso figurado, en expresiones como ula situación de opresión de los trabajadores es insosteniblen, que no consiente el segundo. $Y$ este empleo moral nos interesa aquí vivamente.

Distingos lingüisticos aparte, no tiene sentido hablar de sostenibilidad sin concretar qué es lo sostenible. La sostenibilidad, sin más, es un concepto vacio. En términos aristotélicos, diriamos que la sostenibilidad es una cualidad que debe predicarse de algo; en lenguaje fregeano, que se trata una función insaturada, necesitada de argumento para adquirir valor semántico (Frege, 1891). De esta afirmación pueden derivarse consecuencias de alcance. Una 
primera, especialmente relevante para nuestro tema, es que la sostenibilidad no puede constituir un fin por sí misma, sin especificar de qué se predica.

¿De qué predicamos, pues, la sostenibilidad? ¿Qué creemos o queremos sostenible? Habitualmente, el desarrollo. Así lo entiende también la Real Academia, que no puede definir el término sostenible sin completarlo con aquél: «Dicho de un proceso: Que puede mantenerse por si mismo, como lo hace, p. ej., un desarrollo económico sin ayuda exterior ni merma de los recursos existentes" (RAE, 2005).

Hablar de sostenibilidad es, por lo tanto, las más de las veces hablar de desarrollo sostenible. La noción de desarrollo sostenible presenta una rara peculiaridad, que facilita mucho la labor de quien pretende aclararla o simplemente estudiarla, y es que se le puede poner fecha de nacimiento: $1980^{2}$. No obstante, la data que ha quedado registrada en la mayoría de los libros es el otoño de $1983^{3}$, momento en el que la Organización de las Naciones Unidas crea la Comisión Mundial sobre el Medio Ambiente y el Desarrollo (CMMAD). Las conclusiones de esta comisión, conocidas como Informe Brundtland en honor de su presidente, la por entonces primera ministra de Noruega, Gro Harlem Brundtland, fijan y popularizan la expresión mediante la siguiente definición:

"El desarrollo sostenible es el desarrollo que satisface las necesidades de la generación presente sin comprometer la capacidad de las generaciones futuras para satisfacer sus propias necesidades. Encierra en sí dos conceptos fundamentales:

- el concepto de "necesidades», en particular las necesidades esenciales de los pobres, a las que se debería otorgar prioridad preponderante;

- la idea de limitaciones impuestas por el estado de la tecnologia y la organización social «junto con» la capacidad del medio ambiente para satisfacer. las necesidades presentes y futurası (CMMAD, 1988: cap. 2, \$1) ${ }^{4}$.

Esta formulación ha recibido después numerosas criticas -algunas por adolecer de concreción, las más por pecar de "desarrollismo"- que a veces han desembocado en caracterizaciones alternativas ${ }^{5}$. No obstante, puede pensarse, con David Pearce, que el desarrollo sostenible es, en todo caso, un fin deseable y que, por ende, la tarea pendiente no es la de definirlo, sino la de decidir qué hacer para conseguirlo (Pearce, 1999: 69). Esto es cierto sólo a medias, pues la idea de desarrollo sostenible está también insaturada: desarrollo sostenible, ¿de qué? ¿De la economía, del medio ambiente, de las capacidades humanas, de un plan general de ordenación urbana, ...? También la industria del armamento podria desarrollarse sosteniblemente y eso no la convertiria inmediatamente en deseable...

Seamos generosos y otorguemos la mayor amplitud a la idea, concediendo que aquello que puede desarrollarse sosteniblemente es ni más ni menos que toda actividad humana. Dado que el humano obrar no encuentra, de momento, otro sostén, real o figurado, que la tierra misma (o la Tierra, si se prefiere) y lo que contiene -tampoco cuando trata de extenderse a otros cuerpos celestes- no parece descabellado proponer la siguiente representación (Figura 1):

FIGURA 1.

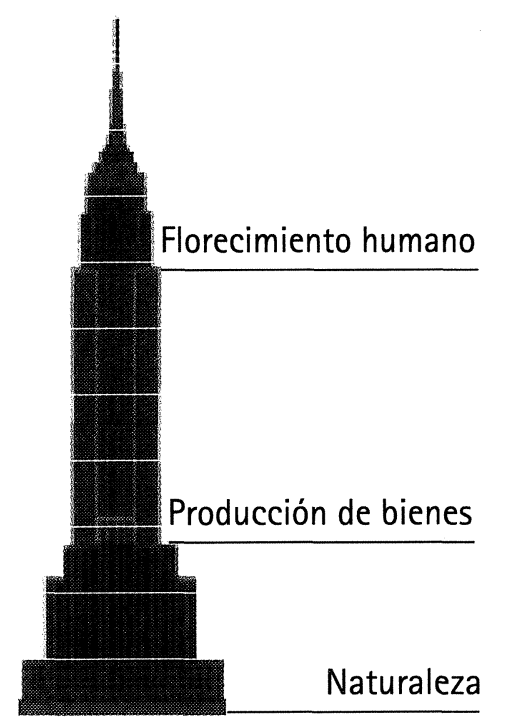

Si esta figura arquitectónica se da por buena, estudiar el posible alcance de la sostenibilidad supondrá revelar su papel en la estructura del edificio. Parece, pues, razonable que comencemos nuestra indagación por sus cimientos. ¿Qué puede significar la sostenibilidad cuando se refiere a la naturaleza?

\section{Sostenibilidad medioambiental: una metonimia $^{6}$}

La idea de naturaleza tiene tanta amplitud semántica, tamaña historia y tal carga filosófica que resulta ya prác- 
ticamente inmanejable. Quizá por eso mismo se prefiere hoy, sobre todo en discursos que pretenden adornarse con la asepsia del lenguaje técnico, el redundante sintagma "medio ambiente".

En castellano, la expresión «medio ambiente» no es precisamente añeja. Su empleo no se vuelve notorio hasta el siglo XX y aun en esa centuria sólo se generaliza a finales de los años sesenta. Ahora, ¿qué es eso del medio ambiente? Cabe suponer que tal conjunción ha de tener un alcance más restringido (y aparentemente más preciso) que el de sus miembros. Da la impresión de que el ambiente designa una parte concreta o una forma particular del medio; que constituye, por tanto, algo diferente de éste. Por otra parte, el término "ambiente" tiene resonancias psicológicas. De hecho, el sintagma de marras se difunde primero, a comienzos del siglo XX, en publicaciones de psicología, y no de zoologia o ecologia ${ }^{7}$. El ambiente podría contemplarse, pues, como el lugar de desenvolvimiento de la acción de los individuos con psique, como la atmósfera que rodea las empresas humanas.

Lo que queda en la intersección que parecen dibujar ambas mitades, el medio y el ambiente es, más que ninguna otra cosa, un escenario, nuestro escenario, compuesto de aqueIlo que acoge nuestra obra sin formar parte del elenco. Mientras que la naturaleza admite, en ciertos imaginarios, la consideración de sujeto con capacidad de acción, impulso y espontaneidad, el medio ambiente se reduce a un mero receptáculo que simplemente reacciona ante a la actuación humana. El medio ambiente recobra asi el sentido quizá más añoso del término "ambiente», el literario, presente en expresiones como "drama de ambiente rural». La naturaleza podia ser hermana con la que compartir, madre de la que aprender, diosa a la que temer; el medio ambiente es un objeto sin personalidad, sin iniciativa, con un poder ciego y menguante, manifestado únicamente en meteoros esporádicos -que, eso sí, aparecen cada vez con más asiduidad y violencia, confirmando los peores augurios climáticos-. Lo natural sigue presentándose como sublime, pero se asimila cada vez más a un telón de fondo, sin protagonismo en la trama del discurrir humano.

Si hemos de procurar su sostenibilidad, debemos al menos tener una noción, siquiera difusa, de sus constituyentes. ¿Qué se supone, pues, forma parte del medio ambiente? ¿Qué distingue este escenario natural de otros escenarios posibles? Probemos primero por intensión. Las notas can- didatas a constituir el rasgo distintivo y aglutinador de los componentes del medio ambiente son tres: la organicidad, la armonía y la autonomía respecto al ser humano.

a) La organicidad es aspirante para quienes pretenden diferenciar el medio ambiente de lo que no lo es por su materia, por su composición física. Desde este punto de vista, la presencia de animales y plantas (de ser posible, silvestres), de "materia viva", se vuelve imprescindible para poder hablar de medio ambiente. No ha de sorprender, por tanto, que las imágenes que mejor representan esta concepción del umedio natural" sean precisamente las de los lugares que congregan al mayor número de especies de seres vivos, como la selva amazónica, una isla exuberante de los mares del sur, la gran barrera de coral o el Serengueti.

Sin embargo, la exigencia de organicidad resulta a todas luces demasiado restrictiva, puesto que la erosión, la capa de ozono, los glaciares o las aguas freáticas, por más que cambien, no están vivas más que en un sentido metafórico, no son orgánicas $y_{1}$ por descontado, forman parte también del medio ambiente que se quiere conservar. Luego la organicidad no nos sirve para separar lo que es medio ambiente de lo que no lo es.

b) Para quienes defienden que el medio ambiente puede definirse por su estructura, la candidata a nota distintiva es la armonia. En efecto, para un buen número de gentes lo natural es lo armónico, lo que funciona sin roces, sin conflictos, sin la intervención corruptora de los humanos. Esta posición en cierto modo tomista ${ }^{8}$ no puede más que ignorar las constataciones de las llamadas ciencias naturales, en particular de la biología, las cuales, al menos desde Darwin (inspirado por Malthus, recuérdese), presentan las relaciones entre seres vivos como resultado de luchas, de conflictos, y no como producto de una armonia primigenia. Tampoco nos vale, entonces, la armonía para distinguir lo que forma parte del medio ambiente de lo que queda fuera de él.

c) El mismo trasfondo tomista, y aun aristotélico ${ }^{9}$, se encuentra en el intento de distinguir el medio ambiente por contraste con la obra humana. En consecuencia, no es extraño que el criterio de la autonomia con respecto al ser humano se tope con todas las dificultades con las que tropezó el Estagirita y alguna más. Por ejemplo, ¿son naturales -es decir, forman parte del medio ambiente- los diques levantados por 
un castor, los panales de una colmena, los nidos de las golondrinas, las estructuras sociales de los chimpancés, ...? Entonces, ¿qué ocurre con las obras humanas, con sus diques, con sus fábricas y campos de cultivo, con sus habitáculos, con sus organizaciones sociales? Si los seres humanos no somos productos artificiales y constituimos una parte tan "natural» de la biosfera (o del planeta, o del universo, o de la unidad que se prefiera) como el resto de los seres vivos, ¿no es la propia actividad humana una actividad natural? ¿No son, por tanto, una pomarada, una vereda o un vertedero también elementos del medio ambiente? La distinción entre lo dado y lo producido parece sumamente frágil.

A menudo se olvida que el "medio ambiente» es inseparable de toda acción, incluida la humana. Aquello sobre lo que se actúa, si es medio, lo es sólo merced al punto de vista: tal o cual franja costera o cordillera, o tales o cuales individuos de una especie animal o vegetal, forman parte del medio ambiente de los seres humanos que los pueblan, divisan, visitan o transforman de la misma manera que el claustro de una catedral es el medio ambiente de los líquenes o las salamandras que nacen y mueren entre sus muros (algunas, incluso, viven exclusivamente ahi, como la salamandra bernardezi ${ }^{10}$, endémica de la catedral de Oviedo), las alcantarillas lo son de las ratas o el intestino humano, de numerosas bacterias. Pero cuando se habla de conservar el medio ambiente, a nadie se le vienen a la cabeza claustros, alcantarillas o tramos de intestino.

La definición (es decir, la aclaración, la distinción) intensional del medio ambiente es imposible sin postular un ámbito antrópico aislado de él. Tal separación es necesaria para dotar de un sentido unitario a la expresión "medio ambienten; el medio ambiente bien conservado seria, entonces, aquello que el ser humano "civilizado" no ha alterado (aún). Si no definimos al menos un determinado grupo humano como fuera del medio ambiente, entonces éste tampoco se puede identificar por oposición a aquél. Sin embargo, pocas delimitaciones habrá tan artificiosas e inverosímiles, no sólo porque ya no existan en el planeta rincones libres de la intervención humana, sino, antes y sobre todo, porque ésta nunca puede separarse totalmente del sustrato físico en el que tiene lugar.

¿Qué ocurre si probamos a delimitar el medio ambiente por extensión? Dragos, calamares, un virus de la gripe, las mareas de San Agustín, la fotosintesis, la migración de los ánsares árticos, la radiación solar, un golfo, el color de un hayedo en otoño, ... Al agrupar toda una serie de elementos diversos bajo el mismo significante, se diluyen sus diferencias, a menudo abrumadoras. Porque, ¿qué relación, aparte de una contigüidad eventual, puede establecerse entre las nieves de enero, una erupción volcánica, el ciclo de Krebs, el aullido de un lobo, el Plasmodium malariae, las Islas Galápagos, un cristal de cuarzo, el sonido de las olas al retirarse entre los cantos rodados? Todos ellos, sin embargo, forman parte del medio ambiente. En negativo, ¿qué no forma parte del medio ambiente? Ya se sabe: lo que vale para todo, no sirve para nada.

Llegamos asi a la metonimia anunciada más arriba: la expresión "medio ambiente» se designa un todo (la physis, al fin y al cabo) con el nombre de una parte, 0 , tal vez, la parte con el nombre del todo. Pero no sabemos de qué parte ni de qué todo se trata. Luego tampoco está claro qué puede significar la sostenibilidad predicada del medio ambiente.

\section{Sostenibilidad económica: un oxímoron}

Se puede argüir que, en realidad, la alteración, el daño o directamente la destrucción del medio no es más (ni menos) que un índice de sostenibilidad de las actividades que se realizan en él. Aun cuando, claro, descrito de otra manera (más edificante y hermosa, por cierto), el problema de la dependencia humana del entorno físico y los peligros que amenazan a quien con su actividad no lo respeta son bien conocidos desde antiguo:

"Había alli una enorme encina, robusta y antiquísima, que era ella sola un bosque; vendas, tablillas conmemorativas y guirnaldas ceñían sus ramas, testimonios de deseos cumplidos. Muchas veces celebraron las driades sus danzas festivas bajo esta encina, y muchas veces rodearon su tronco cogidas de las manos, y su medida era de quince brazos; el resto del bosque era bajo esta encina tanto como la hierba bajo el resto del bosque.

Pero no por eso el hijo de Triopas [Erisicton] apartó de ella el hierro, y ordenó a sus siervos que talaran la encina sagrada. Al ver que vacilaban en cumplir sus órd.enes, le quitó el hacha a uno de ellos y pronunció estas infames palabras: "¡Aunque fuera no ya querido para la diosa, sino la diosa misma, pronto tocará el suelo con su frondosa copa!n Así habló, 
y mientras blandia el hacha para asestarle un golpe de costado, la encina de Deo tembló y emitió un gemido, sus hojas empezaron a palidecer a la vez que las bellotas, y también las largas ramas perdieron su color. Cuando la sacrilega mano hirió el tron$\mathrm{Co}$, de la corteza herida manó sangre, de la misma manera que suele sangrar profusamente la garganta de un poderoso toro cuando cae sacrificado ante el altar. [...] Él sigue adelante con su maldad; por fin, quebrantado por numerosos golpes y arrastrado por cuerdas, el árbol se derrumba, aplastando bajo su peso una gran parte del bosque. Las Driades, todas hermanas, atónitas ante el daño que suponia para el bosque y para ellas mismas, se visten de negro y se dirigen a Ceres con sus lamentos, y le piden que castigue a Erisicton. Ella asintió a sus súplicas, y con un gesto de su cabeza, bellísima, sacudió los campos cargados de mieses maduras; meditó una clase de castigo que habria podido despertar compasión, si no fuera porque él, con sus actos, se había hecho indigno de compasión alguna: atormentarlo con el Hambre. Pero puesto que ella no puede ir en persona, pues los hados prohiben que Ceres y el Hambre se encuentren, se dirige a una divinidad de los montes, una agreste oréada, con estas palabras: «Hay en los extremos confines de Escitia un lugar helado, una tierra triste, estéril, sin mieses y sin árboles. Alli habita el Frio perezoso, la Palidez, el Temblor y el Hambre descarnada: ordénale a ésta que se oculte en las despiadadas entrañas del sacrílego Erisicton, y que no se deje vencer por la abundancia de los alimentos, que sea ella la vencedora cuando se enfrente a mis fuerzas" (Ovidio, 1994: VIII, 301-302).

El Frío, la Palidez, el Temblor y el Hambre no son sólo personificaciones míticas. Casos como el de Nínive o el de la civilización maya fueron bien reales e ilustran una idea popular tan vieja como ellos: es insensato dañar a quien te da de comer. Luego lo que debe resultar sostenible no es el entorno, sino la manera en que nos nutrimos de él, nuestra actividad económica. Ya se ha dicho que lo que normalmente se califica como sostenible no es el medio ambiente, sino el desarrollo. Por su parte, este desarrollo se identifica casi invariablemente con el crecimiento económico. ¿Puede decirse con sentido la sostenibilidad del crecimiento?

Al contrario que los primeros practicantes de la disciplina, como Smith, Malthus o Mill, la economía del siglo XX se dejó seducir por su aparato matemático y se centró más en la modelación y la medida que en la bondad de lo medido; estuvo más interesada por la aritmética política que por la verdadera riqueza de las naciones, y mucho menos por los sentimientos morales. El crecimiento fue su preocupación fundamental, su meta. $Y$ aún lo sigue siendo en los inicios del siglo XXI. Así lo declaraba Sala-i-Martin, en su conocido manual de la materia (Sala-i-Martin, 1994), que se abre con estas palabras:

"Sin ningún género de dudas, la teoría del crecimiento económico es la rama de la economía de la mayor importancia y la que debería ser objeto de mayor atención entre los investigadores económicosı.

El crecimiento económico se confunde habitualmente con el de variables como el PIB o la renta per capita. Pero, como se ha advertido en numerosas ocasiones, "es un error considerar rico un pais sólo porque su PIB per capita resulta elevado, cuando puede estar dilapidando sus activos con un consumo desaforado" (Dasgupta, 2001: 29). Los ingresos no son riqueza, y mucho menos los gastos, que es lo que propiamente miden los índices basados en el PIB o magnitudes similares. Recordemos las palabras de Borges:

«El dinero es abstracto, repeti, el dinero es tiempo futuro. Puede ser una tarde en las afueras, puede ser música de Brahms, puede ser mapas, puede ser ajedrez, puede ser café, puede ser las palabras de Epicteto, que enseñan el desprecio del oro.... (Borges, 2004).

Puede ser, pero no es. El dinero no es bienestar, ni siquiera es propiamente riqueza. De hecho, su acumulación desmesurada (es decir, sin mesura, sin prudencia) puede inducir una disminución de eso que se llama nivel de vida $-y$ no sólo de quienes no tratan habitualmente con tan poderoso caballero. En los últimos años, el crecimiento desmedido del consumo ha traido problemas también al "primer mundo": laborales (la "deslocalización" provocada por la búsqueda feroz de mayores beneficios es uno de ellos), sociales (recordemos que la migración, a menudo trágica, de desplazados por la pobreza a los paises más enriquecidos es también consecuencia de la ingente afluencia de recursos a esos mismos lugares), de salud pública (la extensión de la obesidad constituye un ejemplo especialmente ilustrativo) y, por supuesto, medioambientales (piénsese en la sequia causada no sólo por la ausencia de lluvias, sino, 
sobre todo, por la creciente, y no tan pocas veces disparatada utilización del agua). Estas dificultades alcanzan a todos, independientemente de su nivel de ingresos, pero desde luego agravan en mucho mayor grado los padeci- mientos de los menos favorecidos. La avaricia (¿por qué no llamarla así?) de quienes más tienen se llega a convertir, incluso, en causa directa de miles de muertes (Cuadro 1).

CUAdRo 1. Conflictos más graves relacionados con los recursos naturales desde $1975^{11}$

\begin{tabular}{|l|l|l|}
\hline \multicolumn{1}{|c|}{ País } & \multicolumn{1}{|c|}{ Duración del conflicto } & \multicolumn{1}{c|}{ Recursos } \\
\hline Afganistán & $1978-2001$ & Piedras preciosas, opio \\
\hline Angola & $1975-2002$ & Petróleo, diamantes \\
\hline Angola (Cabinda) & $1975-$ & Petróleo \\
\hline Camboya & $1978-1997$ & Madera, piedras preciosas \\
\hline Colombia & $1984-$ & Petróleo, oro, coca \\
\hline Congo, Rep. del & 1997 & Petróleo \\
\hline Congo, Rep. Dem. del & $1996-1997,1998-2002$ & Cobre, coltan, diamantes, oro, cobalto \\
\hline Indonesia, Aceh & $1975-$ & Gas natural \\
\hline Indonesia, Papúa Occidental & $1969-$ & Cobre, oro \\
\hline Liberia & $1989-1996$ & $\begin{array}{l}\text { Madera, diamantes, hierro, aceite de palma, } \\
\text { cacao, café, marihuana, caucho, oro }\end{array}$ \\
\hline Marruecos & & Fosfatos, petróleo \\
\hline Myanmar & $1975-$ & Madera, estaño, piedras preciosas, opio \\
\hline Papúa Nueva Guinea & $1949-$ & Cobre, oro \\
\hline Perú & $1988-1998$ & Coca \\
\hline Sierra Leona & $1980-1995$ & Diamantes \\
\hline Sudán & $1991-2000$ & Petróleo \\
\hline
\end{tabular}

Así pues, un sistema basado en el crecimiento sostenido es, por definición, insostenible. El crecimiento siempre tiene límites. Cuando no los respeta, acaba, como los tumores, muriendo y matando a la vez. Al menos desde hace treinta años (Meadows \& al., 1972) esta muerte se percibe como verdaderamente posible, pero su amenaza no parece inquietar lo suficiente.

Aun cuando se negara toda verosimilitud a las previsiones catastrofistas, debe admitirse que la aritmética, como el algodón, no engaña: dada la limitación de los recursos, si somos más que nunca y unos consumen más que nunca, es porque otros pueden consumir menos que nunca. Además, según queda patente en el último Informe sobre desarrollo humano de las Naciones Unidas (Watkins, 2005), el desarrollo humano no avanza parejo al crecimiento económico, con lo cual disminuyen los motivos para defender éste como camino hacia aquél. Por otra parte, como afirmaban recientemente Anne y Paul Ehrlich, "el crecimiento económico de los que ya son ricos no es una prioridad política sensata en este momento de la historia humana" (Ehrlich \& Ehrlich, 2004: 137). La promoción de los seres humanos más pobres no pasa por el crecimiento de la economía mundial, sino por su mejora, por su justificación. Mientras esta mejora no tenga lugar, nos seguiremos encontrando con las situaciones reflejadas en los gráficos siguientes (Figuras 2 y 3 ). 
FIGURA 2. Distribución de la población mundial ${ }^{12}$

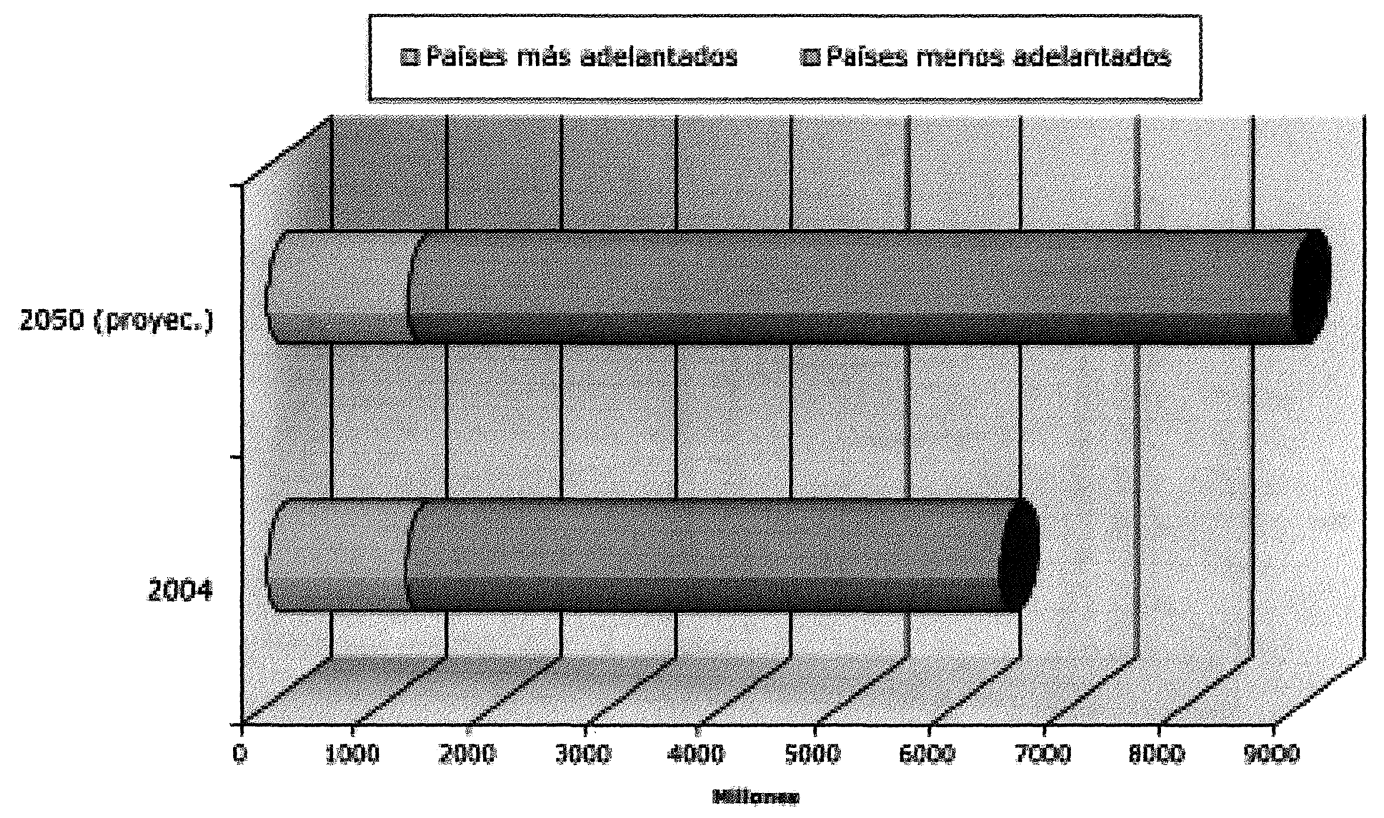

Figura 3. Consumo eléctrico per capita según el nivel de ingresos y desarrollo ${ }^{13}$

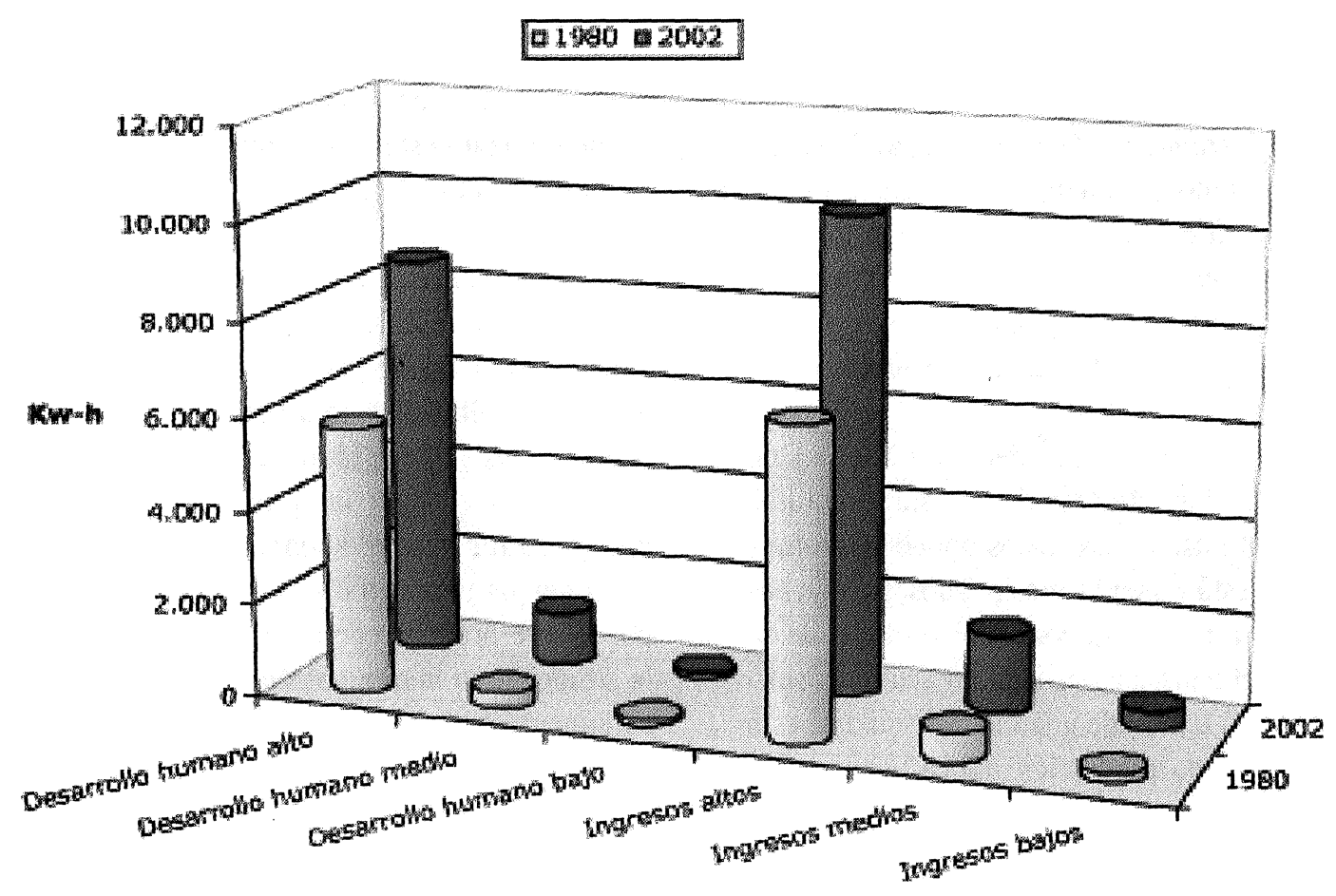

ARBOR CLXXXI 715 SEPTIEMBRE-OCTUBRE (2005) 317-331 ISSN: 0210-1963 
Una situación en la que quienes poseen menos tienen que repartirlo entre más, o en la que quienes más tienen son los que más dañan es, desde todos los puntos de vista (también el económico), insostenible (Figura 4)

Figura 4. Producción de $\mathrm{CO}_{2}$ per capita ${ }^{14}$

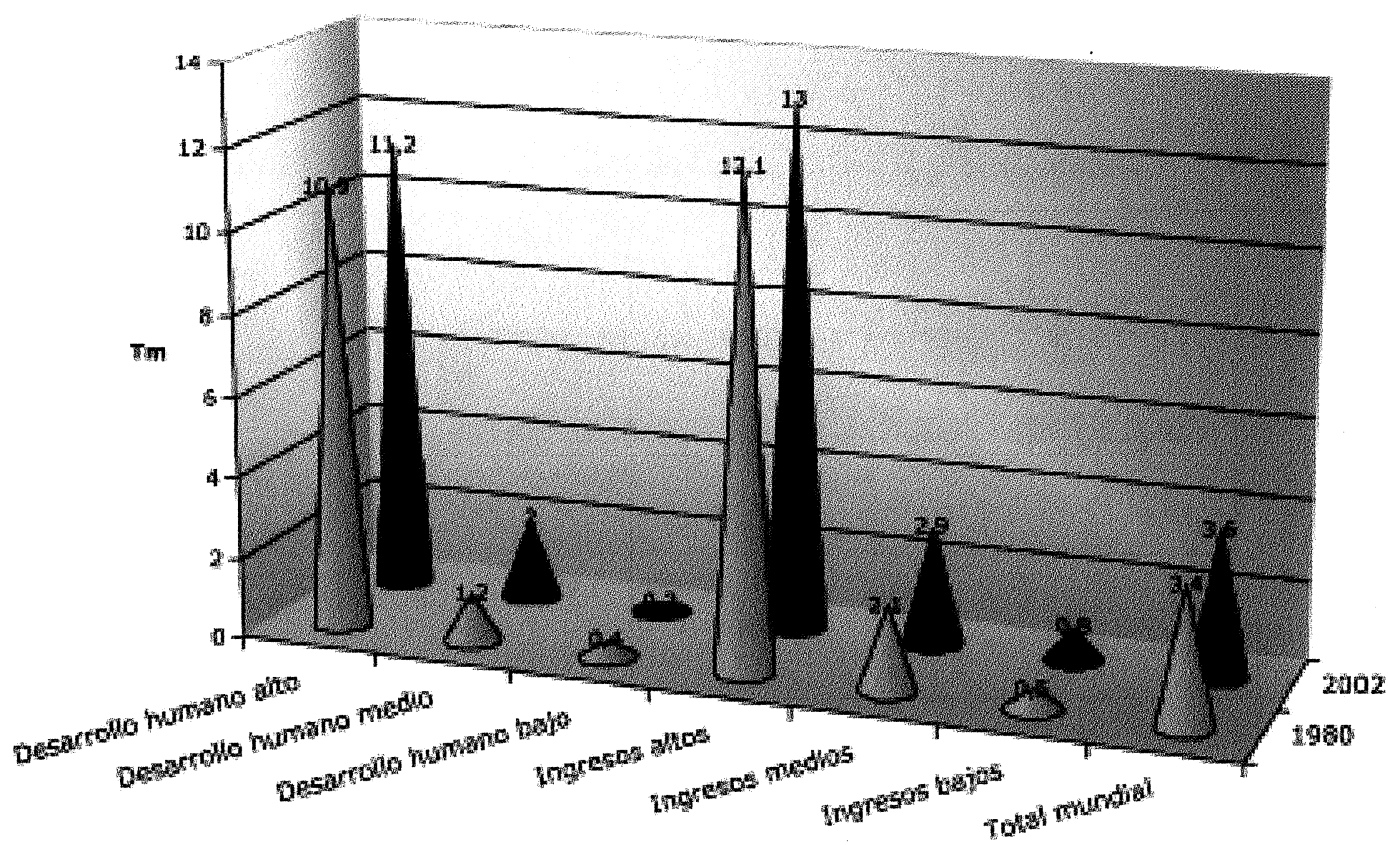

Además del de la correcta distribución intergeneracional de recursos, la sostenibilidad económica debe resolver el problema del mantenimiento de capital: cuando el consumo es excesivo, ya no se puede vivir únicamente de los intereses y el capital comienza a mermar, con lo cual disminuyen también sus intereses, de tal manera que pronto se entra en bancarrota. $Y$ hay quien se atreve a asegurar que ya hemos traspasado la frontera del exceso:

"La humanidad de comienzos del siglo XXI [...] no está viviendo de los intereses de su capital natural, sino del capital mismo. Los suelos agrícolas profundos y fértiles están siendo erosionados en muchas regiones a un ritmo mucho más rápido que el de su regeneración, el agua almacenada en acuíferos subterráneos se está agotando y la biodiversidad se está destruyendo en una proporción nunca vista en los últimos 65 millones de años. Cada año, los políticos se enorgullecen de extender un cheque cada vez más cuantioso contra las cuentas de sus bancos naturales nacionales -sus suministradores de capital natural («la economía creció un 2,3\% durante mi mandaton)- pero nunca comprueban el saldo de su cuenta, que puede estar cayendo en picado" (Ehrlich \& Ehrlich, 2004: 182).

Problemas generalmente asociados a la sostenibilidad, como la deforestación, la pérdida de biodiversidad, la sobreexplotación de los océanos, el empobrecimiento de los suelos cultivables, la urbanización excesiva, la acumulación de residuos de todo tipo, ... implican, qué duda cabe, un daño cierto para las próximas generaciones. Mas ya para nosotros mismos suponen una pérdida de capital que no podemos permitirnos. El mantenimiento de ese capital puede interpretarse como un acto de generosidad, pero, en la situación en la que nos encontramos, ha de verse necesariamente como una cuestión de interés propio. La historia es antigua y $\tan$ simple como un cuento infantil: el de la gallina de los huevos de oro. Que estamos matando a la gallina (si es que no ha perecido ya) queda de manifiesto por el hecho de que, tras décadas de "crecimiento económicon constante, palabras como las siguientes, pronuncia- 
das este mismo año de 2005 por Nelson Mandela, resulten incontestables:

"La inmensa pobreza y la obscena desigualdad son flagelos tan espantosos de esta época -en la que nos jactamos de impresionantes avances en ciencia, tecnología, industria y acumulación de riquezas- que deben clasificarse como males sociales tan graves como la esclavitud y el apartheid" (Watkins, 2005: 4).

Las necesidades y los límites invocados en la definición del Informe Brundtland han sido sistemáticamente despreciadas. Así que las siguientes declaraciones no son exageradas:

"Resulta muy sencillo clasificar un día las cosas como "buenas» o "malas" y no revisar jamás esa clasificación. Durante generaciones, tanto el crecimiento de la población como el del capital fueron considerados absolutamente buenos. En un planeta poco poblado y con recursos abundantes, habia buenas razones para esa valoración positiva. Ahora, con una comprensión cada vez más clara de los limites ecológicos, resulta tentador calificar todo crecimiento como malo" (Meadows, Randers \& Meadows, 2004: 49).

Dada la situación actual, la economía del estado estacionario ${ }^{15}$ no es una mera propuesta teórica, sino una necesidad que antes o después será inevitablemente percibida por todos. Aun cuando se rechacen los principios termodinámicos evocados por Georgescu-Roegen (1971), es evidente que ni el consumo ni la población pueden crecer indefinidamente.

Cierto, la tecnologia -que, recordemos, es contemplada a menudo como el conjunto complementario de "la naturalezan- acude constantemente en auxilio del crecimiento, aportando nuevas formas de producir más con menos. Pero, aun suponiendo que el progreso tecnológico redujera al mínimo el flujo de recursos necesario para alumbrar la cantidad de bienes que los seres humanos precisamos en un determinado momento, este mínimo no podría nunca ser cero. Si las necesidades (es decir, el consumo) y los habitantes humanos del planeta se multiplican sin freno, aun el mínimo necesario llegará a ser demasiado. Que el momento del colapso de un modelo de crecimiento continuo esté más o menos lejano y sea imposible calcular con precisión su llegada no es óbice para considerarlo inevitable. No cabe, pues, más opción que el desarrollo sin crecimiento del consumo, al menos a partir de un punto.

"El desarrollo sostenible es el" desarrollo sin crecimiento -sin crecimiento del caudal de transformación por encima de las capacidades de absorción y regeneración del medio ambiente" (Daly, 1996: 69).

Ahora bien, ¿en qué sentido puede decirse que existe desarrollo en una economía estacionaria? En el estado estacionario se podrán llevar a cabo, seguramente con mayores éxito y justicia, innúmeras empresas (aqui en el sentido de actividades), pero serán éstas, y no "la economia", las que se desarrollen. La estabilidad, como demuestra su discusión entre economistas, no es un fin económico, sino moral y, si ahora parece inevitable plantearla, no es por sus bondades teóricas, sino por las limitaciones físicas de la actividad humana. En definitiva, lo sostenible en el ámbito de la economía no tiene por qué ser el desarrollo (sobre todo el de quienes están más que desarrollados), ni, por supuesto, el crecimiento. La sostenibilidad económica sólo resulta razonable cuando se piensa en las relaciones de producción e intercambio que los seres humanos necesitamos para bienvivir (no meramente para sobrevivir), y no en la senda más o menos expansiva de ciertas variables. Pero el bienvivir no es algo que se pueda someter a la disciplina económica.

La idea de desarrollo sostenible constituye, por tanto, un verdadero oximoron: lo que se desarrolla creciendo no puede hacerlo sosteniblemente. La contradicción, además, no puede resolverse con criterios económicos porque el desarrollo desborda abundantemente el recipiente de la economía.

\section{Sostenibilidad ética: una tautología}

Las actividades humanas trascienden (o eso cabe esperar, al menos) la esfera de lo económico. Incluso aceptando la muy discutible tesis de que «el orden de la sociedad es sólo mediatamente político, e inmediatamente económico" (Habermas, 1994: 77), el orden mediado también está ahi y permite que se opere en él. La economía no agota la explicación ni proporciona la norma toda del actuar humano. Bernard Shaw se equivocaba, desde luego, al conceder a la disciplina económica el título de "arte de sacar el mejor partido de la vidan. Esa labor correspondió siempre a

ARBOR CLXXXI 715 SEPTIEMBRE-OCTUBRE [2005) 317-331 ISSN: 0210-1963 
la filosofía (salvo, claro, que entendamos el mejor partido en el sentido monetario estrecho, por otra parte hoy tan frecuente). De hecho, la delimitación del bienvivir ha sido siempre el objetivo de la ética.

Ya en la definición canónica citada más arriba se incluia el deber intergeneracional como ingrediente caracteristico del desarrollo sostenible, dando así cabida a la ética en la cuestión de la sostenibilidad. Sin embargo, y al contrario de lo que muchos, como Solow, afirman, el problema de la sostenibilidad no es solamente "una cuestión de equidad distributiva entre el presente y el futuron (Solow, 2000: 134-135). Una pluma (habria que decir un teclado, seguramente) más autorizada que la que traza estas líneas expresaba así esta misma idea:

"La divergencia de intereses que causa daños medioambientales desmesurados y amenaza el desarrollo sostenible no es la que se da entre las generaciones actuales y las venideras, sino la que enfrenta en el presente al contaminador con el resto de sus contemporáneos [...] La amenaza a la sostenibilidad surge del desprecio (por parte de individuos que consumen y producen contaminando) del bienestar de los demás, no del desprecio (por parte de la generación presente) del bienestar de las generaciones futuras» $(\mathrm{Ng}, 2004: 152)$.

Tampoco estamos ante una cuestión de "ética de la empresa». La sostenibilidad ética no se consigue uinternalizando" las "externalidades" medioambientales y sociales generadas en las actividades productivas y consuntivas. No se trata, como parecen pensar con complacencia muchos gobiernos actuales, de aplicar una batería más o menos exigente de medidas correctoras de ciertos fallos de mercado. El mercado no es el problema porque, aunque se haya malinterpretado hasta el aburrimiento la ocurrencia que llevó a Adam Smith a dotarlo de manos (si bien invisibles), el mercado no actúa: lo hacen quienes concurren en él. Son éstos los que pueden obrar sostenible o insosteniblemente.

En última instancia, lo que es sostenible o deja de serlo es una forma de vida, unas costumbres o mores, una moral. Por eso la discusión acerca de la sostenibilidad es una discusión ética. Lo cual no quiere decir que no merezca en ocasiones los calificativos de ecológica, económica o politica. Es todo esto precisamente porque se sitúa en el plano de la ética, que cubre a los otros tres (cosa que no necesariamente ocurre a la inversa). Ninguna novedad:

"Ciertamente, existen en economía política grandes principios generales, en los que muy rara vez se producen excepciones, y límites netos en los que casi siempre puede confiarse como guías seguros, pero aun al examinarlos se encontrará que se asemejan, en la mayor parte de sus características, a las grandes normas generales de la moral y la política, fundadas en las pasiones e inclinaciones conocidas de la naturaleza humana: y ya nos refiramos a las cualidades del hombre, o a las de la tierra que está destinado a cultivar, nos veremos obligados a reconocer que la ciencia de la economía política se asemeja más a las ciencias morales y políticas que a las matemáticas» (Malthus, 1946: 3).

La sostenibilidad, deciamos al principio, no es más que una función insaturada, una medida, un cedazo. Cedazo que no puede convertirse en el motor, pero si en la prueba del nueve de las buenas acciones (de cada individuo y de cada sociedad), en la versión temporal del imperativo categórico kantiano. Si su enunciado "espacial" adquiere virtud reveladora en nuestro mundo atestado (Riechmann, 1995: 16), su versión temporal no le va a la zaga:

"Obra de forma que la máxima de tu conducta pueda convertirse en ley de vigencia indefinidan.

Es verdad que cualquier regla moral extraída únicamente de la sostenibilidad está condenada al mero formalismo categórico y que, como tal, puede padecer las mismas criticas que a lo largo de los últimos siglos se han dirigido contra la ética kantiana y sufrir idénticas limitaciones. No obstante, en un mundo lleno ${ }^{16}$ parece difícil no aspirar a su cumplimiento, siquiera parcial. Si ya en las primeras décadas del siglo XX el fenómeno de lo lleno era evidente ("Las ciudades están llenas de gente. Las casas, llenas de inquilinos. Los hoteles, llenos de huéspedes. Los trenes, Ilenos de viajeros. Los cafés, llenos de consumidores. Los paseos, llenos de transeúntes. Las salas de los médicos famosos, llenas de enfermos. Los espectáculos, como no sean muy extemporáneos, llenos de espectadores. Las playas, llenas de bañistas. Lo que antes no solía ser un problema, empieza a serlo casi de continuo: encontrar sitio. Nada más. ¿Cabe hecho, más simple, más notorio, más constante en la vida actual?», escribía Ortega en 1930), 
más lo es ahora, cuando la población de entonces se ha multiplicado por más de tres.

En esta situación de congestión resulta vital volver visibles las consecuencias de nuestras acciones, que se convierten inconsciente o perversamente en causas de males de todo tipo. Muchos de nuestros problemas se aliviarían si pudiésemos apreciar cómo los provocamos. No vemos adónde van a parar nuestras basuras ni cuántas son, no vemos los CFC salir de nuestra vieja nevera y subir a deshacer la capa de ozono, ni vemos morir los corales de la Gran Barrera, ni cómo se quedan sin trabajo miles de personas en paises cercanos, ni cómo se explota a otras en regiones más lejanas, ni cómo se mata por el petróleo (aunque lo oigamos), ni cómo baja el nivel de agua del acuífero o del embalse cuando abrimos el grifo. El imperativo de corte kantiano que se ha enunciado contribuye a paliar tan lamentable ceguera, no por ser kantiano ${ }^{17}$, sino por despertar la conciencia de las consecuencias diferidas de nuestras decisiones. Los seres humanos somos muchos, demasiados ya, y necesitamos herramientas para juzgar las consecuencias colectivas de la acumulación de actos individuales, sobre todo cuando, como ocurre ahora, tales actos se repiten casi mimética y simultáneamente por doquier. Cuando el colectivo es la totalidad de la especie y la amenaza parte de sus mismos miembros, a menudo inconscientemente, la mesura (entendida como conjunción de austeridad y prudencia) se convierte en necesidad perentoria. Es verdad, "escarnecer la filosofía de la fuerza y de la supremacia es como escarnecer un exceso de bilis o un dolor de muelas» (Chesterton, 1964: 6), pero, dadas las circunstancias, no resulta en absoluto ocioso insistir en la iniquidad de los modelos que equiparan éxito colectivo y acumulación individual. Mandeville no nos sirve cuando salta a la vista que muchos vicios privados sólo traen mayores vicios públicos.

¿Quiere lo anterior decir que el criterio de sostenibilidad sólo se aplica a colectivos? No: sirve para ponderar acciones concretas, independientemente de quién las realice. En su forma general, como se ha repetido ya, la sostenibilidad está tan vacía como un metro $y$, asi como éste mide todo lo que ocupa, aquélla puede cribar todo lo que dura. Debe tenerse en cuenta que la sostenibilidad efectivamente filtra, separa impurezas, que funciona mejor como criterio de maldad (técnica y moral) que de bondad: su incumplimiento es, desde luego, indeseable, pero su satisfacción no implica inmediatamente la excelencia de la acción juzgada. Que toda acción ética es una acción sostenible es, evi- dentemente, una tautología: todo lo que resulta insostenible moralmente es insostenible. Lo que ya no es cierto es que todo lo sostenible deba tomarse por moralmente aceptable. Recordemos el ejemplo de la industria armamentistica aludido antes.

Por lo demás, es evidente que la sostenibilidad es un ideal regulativo y, por lo tanto, no puede realizarse por completo. Ahora bien, como tal ideal regulativo, debe presidir todas la acciones que pretendan aproximarse a él. La sostenibilidad es, por tanto, solamente un criterio, y un criterio sobre todo moral. Un criterio que, por fortuna, sirve para orientar las actuaciones políticas.

\section{Gobernanza sostenible: epitome}

El ámbito de aplicación del criterio de sostenibilidad es el mismo que el de la política: la vida social de los seres humanos. Por eso seria deseable que su interpretación superase los esquemas sectoriales, como el que se ofrece en la figura 5 .

Aunque los tres ámbitos recogidos en la Figura 5 coincidan con los pilares que se invocaban en la Declaración de Johannesburgo:

"Nosotros, los representantes de los pueblos del mundo", asumimos la responsabilidad colectiva de promover y fortalecer, en los planos local, nacional, regional y mundial, el desarrollo económico, desarrollo social y la protección ambiental, pilares interdependientes y sinérgicos del desarrollo sostenible» (ONU, 2002: §5),

la noción de sostenibilidad no puede inscribirse en el circulo estrecho del desarrollo sin verse severamente cercenada, y aun traicionada. Además, insistimos, desarrollo sostenible, ¿de qué? Si no se dice, sus pilares, sean tres o treinta veces tres, no podrán estar bien asentados. Cada dia aparecen nuevos ejemplos de que el desarrollo económico (o sea, el crecimiento del peculio agregado), el desarrollo social (que no está muy claro en qué ha de consistir, pero en todo caso tendrá que ver con la satisfacción personal de los miembros de la sociedad) y la protección del medio ambiente (salvando la vaguedad del sintagma) resultan demasiado a menudo metas mutuamente excluyentes. Lo deseable no es buscar un arreglo de compromiso como el 
que se desprende de la figura 5 , sino encontrar un auténtico equilibrio estable que deje fuera las actividades incompatibles entre si y, por tanto, simultáneamente insos- tenibles. La imagen representativa no es la de la intersección de conjuntos, sino la de la imbricación lo más amplia posible de todos los ámbitos políticos.

FigURA $5 .{ }^{18}$

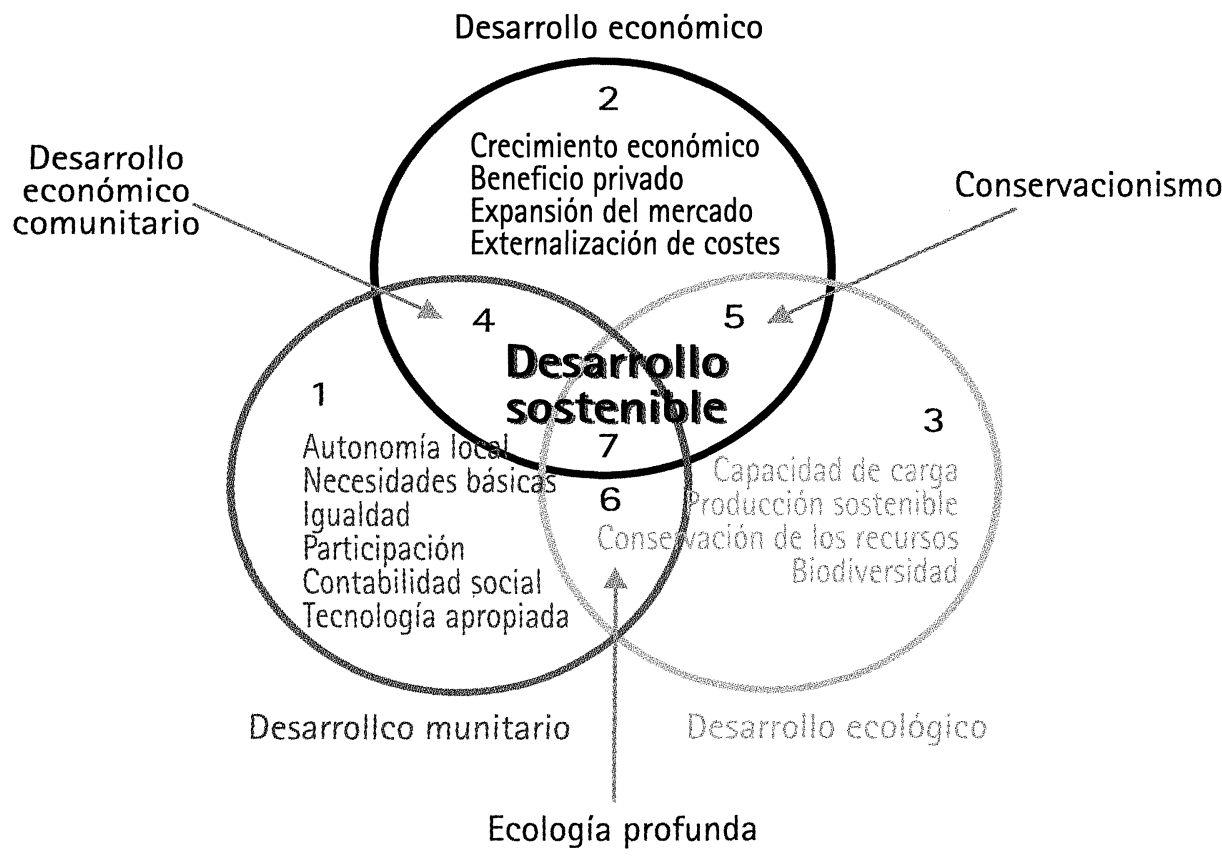

Un equilibrio tal depende, en todo caso, de los fines adoptados por las sociedades que se lo propongan y en ningún caso determina qué es lo que efectivamente está equilibrado. El equilibrio, como la sostenibilidad, también es un concepto insaturado. Aun así, pueden enumerarse algunos requisitos que debe satisfacer una gobernanza que se quiera sostenible:

a) Derribar el ídolo del crecimiento y despertar de la ilusión del supermercado: las estanterías no se llenan solas por las noches. La cantidad y variedad de los bienes de los que podemos disponer no dependen directamente de nuestro dinero, sino, antes, de los recursos con los que se producen y de los sistemas que aseguran la neutralización de sus residuos. Tenemos límites, especialmente para el consumo y el depósito de residuos. La gobernanza sostenible debe ser capaz de defender una cierta noción de suficiencia (por no decir de austeridad, palabra de resonancia casi violenta en estos tiempos y esta parte del mundo). ¿Cuánto es suficiente? No está claro, pero si lo está que la idea de que lo que hay nunca es suficiente es absurda y peligrosa. En cualquier caso, la noción de suficiencia no es primariamente económi$c a$, ni natural o biológica, sino moral.

b) Atender, sobre todos los demás asuntos, el de la educación, como se desprende de lo antedicho. La educación es la que da forma a los modos de vida, a los hábitos de consumo, a las relaciones económicas en general, a la implicación política, a la actitud estética y aun a la impronta sobre el medio, que pueden propiamente calificarse como sostenibles o insostenibles. Sólo con educación, individual y colectiva, podrán hacerse patentes todos los problemas aludidos a lo largo de estas líneas, y sin ella no podrá nunca conseguirse una gobernanza sostenible: como Platón advertía en su Carta VII (336b), en los excesos de la ignorancia "hunden sus raices todos los males del mundo; ella los hace brotar $y_{1}$ a la postre, acaba produciéndoles a los que la han sembrado el fruto más amargon. 
c) En relación con lo anterior, procurar la máxima transparencia. Sin transparencia es imposible aplicar el criterio de sostenibilidad, puesto que su ausencia impide calcular correctamente las consecuencias de las acciones emprendidas, propias y ajenas. Hoy, además, disponemos de unos magníficos medios para conseguirla, en particular las redes de telecomunicaciones y los dispositivos de almacenamiento de datos. No cabe duda de que las sociedades más transparentes son también las más sostenibles (UNECE, 1998; Spash, 2001; Gouldson, 2004). La presencia de numerosos licenciados Vidriera (permítasenos la licencia, aunque a alguien pueda parecer vidriosa), aun en forma de colectivo o de medio de comunicación, facilitaría enormemente el tránsito hacia un modo de vida sostenible.

La sostenibilidad es un requerimiento físico (medioambiental, si se quiere), económico y moral. Por eso es también un deber político. No un deber moral, económico o «medioambiental» del político (por más que la persona dedicada a la política tenga sus deberes y su cumplimiento ayude sin duda a satisfacer el criterio de sostenibilidad), sino una condición de posibilidad de la buena política, de la gobernanza. Con lo cual carece de sentido una política sectorial sobre la sostenibilidad o el desarrollo sostenible, igual que carece de sentido un ministerio de honradez o de civismo (lo cual no quiere decir que en un momento dado, por ejemplo este, no esté de más lanzar programas sectoriales encaminados a conseguir la sostenibilidad en el mayor número de ámbitos).

Gobernanza y sostenibilidad vienen a ser dos conceptos casi conjugados: la primera no puede darse sin la segunda, puesto que la propia definición de bondad incluye la de eficacia, que no puede darse si aquello de lo que se predica está limitado por su propia existencia (es decir, una actividad insostenible no puede nunca calificarse como verdaderamente eficaz, puesto que acaba consigo misma).

Una gobernanza sostenible es ni más ni menos que aqueIla que se puede sostener; esto es, aquella cuyo ejercicio permite mirar atrás y adelante sosteniendo la mirada (sin apartarla de espanto ni bajarla por vergüenza). El buen gobierno es aquel que pondera sus acciones, no daña sin querer, decide con el respaldo de la razón y de los gobernados, proyecta como si tuviera que asumir todas las consecuencias de sus iniciativas, y no tiene que esperar más amenaza que la de la violencia ilícita; un gobierno, en definitiva, cuyos logros pueden sostenerse, prolongarse indefinidamente en el tiempo sin que se vuelvan contra él. El respeto al "medio ambiente" es sólo un indicador, si bien importantisimo, de que el gobierno de la sociedad que lo ejerce y lo propaga es, efectivamente, sostenible.

En todo caso, por muy vacía que se considere la idea de sostenibilidad, el gobierno (o la gobernanza), si no es sostenible, resulta insostenible. La cita con la cual se abría el capitulo es una verdad de Pero Grullo que conviene tener siempre presente. Si algo se quiere mantener, podrá discutirse cómo lograrlo, pero no si lograrlo.

El criterio de sostenibilidad elimina, pero no propone; condiciona, pero no determina. La sostenibilidad no es una meta, ni siquiera un camino, sino una guía en el camino hacia la meta, que sólo nos ayuda a fijarla porque descarta algunos fines por inalcanzables. Así pues, el primer paso hacia la sostenibilidad no puede darse si no se determina antes la dirección que se desea tomar. Ya el gato se lo confirmó a Alicia: cuando no importa llegar a un sitio o a otro, entonces da lo mismo un camino que otro. ¿A qué sitio queremos llegar nosotros, como individuos, como sociedades, como especie? Cada quien verá qué responde. En todo caso, que tenga presente que el camino hacia lo mejor es efectivamente el de lo mejor, no el de lo mayor. 


\section{NOTAS}

1 Esto es, hasta finales de 2005 o la vigésima tercera edición del Diccionario.

2 En una publicación de la International Union for the Conservation of Nature and National Resources (1980), World Conservation Strategy, Gland, Suiza: IUCN. (Cit. en Jacobs, 1991). No obstante hay otros precedentes, como Stirers, Robert L. (1976), The Sustainable Society: Ethics and Economic Growth, Philadelphia, Penn.: Westminster Press (libro de difícil acceso, citado en Velasquez, 2002). Para antecedentes más remotos, puede consultarse Lumley \& Armstrong, 2004.

3 Casualmente este es el mismo año en el que Paul Romer escribe su tesis doctoral sobre rendimientos crecientes y crecimiento a largo plazo, punto de inflexión en la teoría reciente del crecimiento económico.

4 El Informe Brundtland se publicó en inglés en 1987. La Real Academia recoge esta definición de desarrollo sostenible casi literalmente en la próxima edición de su diccionario: "desarrollo económico que, cubriendo las necesidades del presente, preserva la posibilidad de que las generaciones futuras satisfagan las suyas" (RAE, 2005).

5 Pueden verse algunas en Costanza, 1991; Daly, 1996; Fernández-Bolaños, 2002; o Bell \& Morse, 2003.

6 Una buena parte de las ideas desarrolladas en este apartado ha aparecido también en "Tecnociencias y medio ambiente», en Ausín, T. y Rodríguez Aramayo, R. (eds.) (2005): Moral, ciencia y sociedad en la Europa del s. XXI. Theoria cum Praxi.

7 No obstante, la obra más antigua en cuyo título hemos encontrado la expresión si es "de ciencias naturales». Se trata de Importancia del conocimiento general de la atmósfera ó medio ambiente, $y$ estudio fisico acerca de su temperatura, discurso escrito para el ejercicio del doctorado en la Facultad de Medicina de la Universidad Central de Madrid por Manuel Manzaneque y Montes, e impreso en Madrid en la Imprenta, Fundición y Estereotipia de D. Juan Aguado, en 1875. Su interés doctoral no era, por cierto, ecológico, sino propiamente médico.
8 "Lo que las criaturas reciben de Dios les es natural. Pero lo que se hace por el hombre en las cosas naturales no según la condición de éstas, tiene carácter violenton (Summa Theologica, I, q. 103, a. 1).

9 Recuérdese la distinción entre lo que es por arte y lo que es por naturaleza.

100 Salamandra maculosa forma Bernardezi, como la describió en 1928 Wolterstorff. Se trata, curiosamente, de una salamandra vivípara que, en su día, los canteros reprodujeron en la fábrica del templo. Parece que sólo tras la visita del antedicho zoólogo germano se cesó definitivamente de atribuir el estado de gestación en que parecia estar la figura a la imaginación o la torpeza del artista.

11 Fuentes: Bannon \& Collier, 2003; Watkins, 2005.

12 Elaboración propia a partir de datos contenidos en UNFPA, 2004.

13 Elaboración propia a partir de datos contenidos en UNFPA, 2004.

14 Elaboración propia a partir de datos contenidos en UNFPA, 2004.

15 Para una exposición sistemática de la misma puede consultarse Daly, 1991.

16 La expresión es de Herman Daly.

$17 \mathrm{Ha}$ de quedar para otro lugar la discusión sobre los matices que adquiere el imperativo cuando se toma como imperativo político, colectivo, y no como mero principio de conducta individual. Podria incluso ensayarse una lectura política de la ética kantiana incompatible con muchas de las interpretaciones usuales. Pero no aquí.

18 Basada en Bell \& Morse, 2003: 4.

\section{Bibliografía}

Bannon, I. \& Collier, P. (eds.) (2003): Natural Resources and Violent Conflict: Options and Actions. Washington, DC: Banco Mundial.

Bell, S. \& Morse, S. (2003): Measuring Sustainability: Learning from Doing Londres: Earthscan.

Borges, J.L. (2004): El Zahir, en El Aleph, Barcelona: Destino/ Emecé.

Bossel, H. (1999): Indicators for sustainable development: theory, method, applications: a report to the Balaton Group, Winnipeg: International Institute for Sustainable Development.

Chesterton, G.K. (1964): Sentimental Literature, en The Spice of Life and Other Essays, Beaconsfield: Darwen Finlayson. (Trad. al español (1997), Literatura sentimental, en Ensayos, México: Porrúa; también en http://www.dur.ac.uk/ martin.ward/gkc/books/Spice_Of_Life.html).

CMMAD (1988): Nuestro futuro común, Madrid: Alianza.

Costanza, R. (ed.) (1991): Ecological Economics: The Science and Management of Sustainability, Nueva York: Columbia University Press.

Daly, H.E. (1991): Steady State Economics,

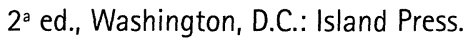

Daly, H.E. (1996): Beyond Growth, Boston: Beacon Press.

Dasgupta, P. (2001): Human Well-being and the Natural Environment, Oxford: Oxford University Press.

Ehrlich, P. \& Ehrlich, A. (2004): One with Nineveh: Politics, Consumption, and the Human Future, Washington: Island Press.

Fernández-Bolaños, A. (2002): Economía y política medioambiental: Situación actual y perspectivas en la Unión Europea, Madrid: Pirámide.

Frege, G. (1891): Funktion und Begriff, en (1962), Funktion, Begriff, Bedeutung. Fünf logische Studien, Göttingen: Günther Patzig. (Trad. española (1996), Función y concepto, en Escritos filosóficos, Barcelona: Critica; también en (1984) Estudios sobre semántica, Barcelona: Ariel. 
Georgescu-Roegen, N. (1971): The Entropy Law and the Economic Process, Cambridge, Mass.: Harvard University Press. (Trad. castellana (1996), La ley de entropía y el proceso económico, Madrid: Fundación Argentaria).

Gouldson, A. (2004): Risk, regulation and the right to know: exploring the impacts of access to information on the governance of environmental risk, Sustainable Development, 12, 136-149.

Habermas, J. (1984): Ciencia y técnica como ideología, Madrid: Tecnos.

Jacobs, M. (1991): The Green Economy: Environment, Sustainable Development and the Politics of the Future, Londres: Pluto Press.

Lumley, S. \& Armstrong, P. (2004): Some of the Nineteenth Century Origins of the Sustainability Concept, Environment, Development and Sustainability, 6 , 367-378.

Malthus, T.R. (1946): Principios de economía política, Méjico: F.C.E.

Meadows, D.H., Meadows, D.L., Randers, J., Behrens, W.W. (1972): The Limits to Growth: A Report for the Club of Rome's Project on the Predicament of Mankind, Nueva York: New American Library. (Trad. castellana (1972): Los límites del crecimiento: informe al Club de Roma sobre el predicamento de la humanidad, México: F.C.E.)

Meadows, D.H., Randers, J. \& Meadows, D.L. (2004): Limits to Growth: The 30-Year Update, White River Junction: Chelsea Green.

$\mathrm{Ng}$, Y.-K. (2004): Sustainable development: a problem of environmental disruption now instead of intertemporal ethics, Sustainable Development, 12, 150-160.

ONU (2002): Declaración de Johannesburgo. Disponible en http://www.un.org/ spanish/conferences/wssd/documents.html.

Ovidio (1994): Metamorfosis, 16 a ed., Madrid: Espasa Calpe.

Pearce, D. (1999): Economics and Environment. Essays on Ecological Economics and Sustainable Development, Aldershot: Edward Elgar. Platón (1993): Cartas, Madrid: Akal.

Real Academia Española (2005): Diccionario de la lengua española, avance de la vigésima tercera edición, http://www.rae.es.
Riechmann, J. (1995): Desarrollo sostenible: la lucha por la interpretación, en Riechmann, J. et al., De la economía a la ecología, Madrid: Trotta/ Fundación $1^{\circ}$ de mayo.

Sala-i-Martin, X. (1994): Lecture Notes on Economic Growth, Barcelona: Universitat Pompeu Fabra, $2^{\text {a }}$ ed. (Trad. castellana (1999): Apuntes de crecimiento económico, Barcelona: Antoni Bosch).

Solow, R.M. (2000): Sustainability: an economist's perspective, en: Stavins, R.N. (ed), Economics of the Environment: Selected Readings, Nueva York: Norton, 131-138.

Soubbotina, T.R. (2004): Beyond Economic Growth: An Introduction to Sustainable Development, $2^{\text {a }}$ ed., Washington: Banco Mundial; disponible en http://www.worldbank.org/depweb

Spash, C. (2001): Broadening democracy in environmental policy processes, Environment and Planning C, 19, 475-481.

UNECE (Comisión Económica de las Naciones Unidas para Europa) (1998): Convention on Access to Information, Public Participation in Decision Making and Access to Justice in Environmental Matters, Aarhus: UNECE.

UNFPA (Fondo de Población de las Naciones Unidas) (2004): Estado de la población mundial 2004. El consenso de El Cairo diez años después: población, salud reproductiva y acciones mundiales para eliminar la pobreza, Nueva York: UNFPA. También en http://www.unfpa.org/ publications/

Velasquez, M.G. (2002): Business Ethics: Concepts and Cases, $5^{\mathrm{a}}$ ed., Upper Saddle River, NJ: Prentice Hall.

Watkins, K. (ed.) (2005): Informe sobre desarrollo humano 2005. La cooperación internacional ante una encrucijada: ayuda al desarrollo, comercio y seguridad en un mundo desigual, Madrid: PNUD/ Mundi-Prensa Libros. También en http://www.un.org 